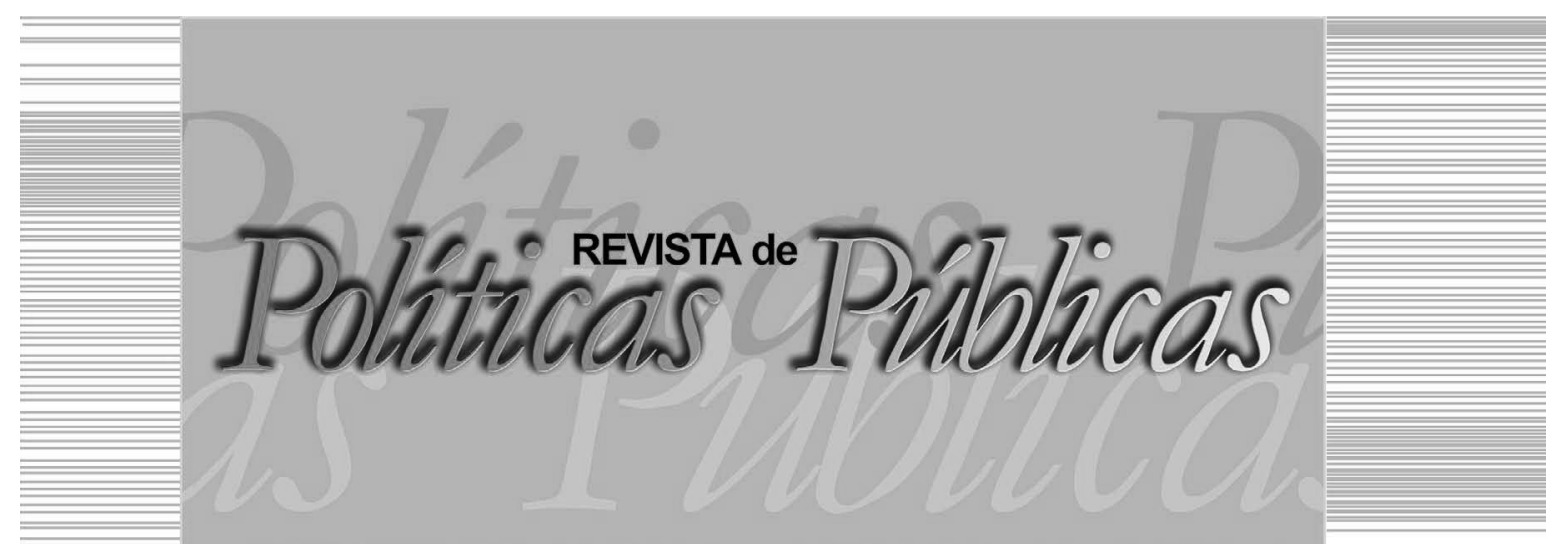

\title{
TRABALHO E PROTEÇÃO SOCIAL NA ACUMULAÇÃO FLEXIVEL: individualização e gerenciamento do risco social
}

\author{
Francilene Soares de Medeiros Costa
}

\section{Resumo}

O objetivo deste artigo é problematizar as mudanças nas perspectivas que informam a proteção social pública, situando as principais tendências no contexto da acumulação flexível. Trata-se de um estudo de caráter bibliográfico, no qual identificamos que três principais justificativas influenciaram a construção na noção de proteção social desde que o Estado social entrou na pauta pública como um dos seus principais provedores: as doutrinas dos riscos; dos direitos e das necessidades. Apesar de sempre ter havido tensão entre essas doutrinas, no contexto da acumulação flexível e de profundas modificações na regulação social e do trabalho, tem prevalecido a linguagem do gerenciamento individual dos riscos, em detrimento da proteção social como direito. O estudo aponta, também, que esse quadro se agrava nos países de capitalismo periférico e dependente, onde prevalecem estratégias mais agressivas de flexibilização.

Palavras-chave: Trabalho, proteção social, flexibilização.

1 Assistente Social. Doutora em Geografia pela Faculdade de Ciências e Tecnologia da Universidade Estadual Paulista "Jíulio de Mesquita Filho" (Unesp) - Presidente Prudente. Professora da Faculdade de Serviço Social da Universidade Federal do Pará (UFPA). E-mail: francilenesoares@yahoo.com.br; francilene@ufpa.br / Universidade Federal do Pará - UFPA: Rua Augusto Côrrea, 01, Guamá, Belém-PA. CEP: 66075-110. 


\author{
WORK AND SOCIAL PROTECTION IN FLEXIBLE \\ ACCUMULATION: Individualization and management of social \\ risk
}

\begin{abstract}
The aim of this paper is to discuss the changes in perspectives that inform the public social protection, placing the main trends in the context of flexible accumulation. This is a bibliographical study, in which we identified that three main justifications have influenced the construction of the notion of social protection since the welfare state entered the public agenda as one of its main providers: the doctrines of risk; rights and needs. Although there has always been tension between these doctrines, in the context of flexible accumulation and profound changes in social and labor regulation, the language of individual risk management has prevailed, to the detriment of social protection as a right. The study also points, that the situation worsens in countries with peripheral and dependent capitalism, where more aggressive strategies of flexibilization prevail.

Key words: Work, social protection, flexibilization.
\end{abstract}

\title{
1 INTRODUÇÃO
}

$\mathrm{O}$ atendimento à diversidade de carecimentos e necessidades humanas faz da proteção social uma prática longeva na história. No entanto, as respostas protetivas são operadas de acordo com os níveis de sociabilidade que se alcança em determinado grupo social. De acordo com Castel (1998), o primeiro nível seria o da sociabilidade primária, ou próxima, que envolve o pertencimento a uma determinada família, grupo de amigos, vizinhança e comunidade em geral, o qual garantiria a proteção social ao indivíduo por meio de uma rede solidária de estatuto privado ou particular. O nível secundário se referiria às provisões realizadas em âmbito institucional, seja público ou privado, que seriam garantidas pelo Estado, pelas empresas ou organismos não governamentais. O segundo nível será o foco das nossas reflexões.

Embora a dimensão primária ou privada da proteção social não tenha deixado de existir no decorrer do tempo, determinadas mudanças societais caminharam para que ocorresse uma maior extrapolação para o âmbito público, complexificando-a e, ao mesmo tempo, evidenciando seu caráter contraditório, sobretudo no contexto capitalista. 
Apesar de muito fluido e controverso, a noção basilar que confere a possibilidade de estruturação de um conceito de proteção social seria que todas as suas ações a identificam enquanto ampla medida de bem-estar. (PEREIRA, 2013a). Nesse sentido, pode ser definida como um "[...] conjunto de iniciativas públicas ou estatalmente reguladas para a provisão de serviços e benefícios sociais visando enfrentar situações de risco social ou privações sociais." (JACOUD, 2009, p. 58). Já na definição de Leite (1978, p. 16), a proteção social diz respeito "[...] a um conjunto de medidas de caráter social destinadas a atender a certas necessidades individuais; mais especificamente, às necessidades individuais que, não atendidas, repercutem sobre os demais indivíduos e em última análise sobre a Sociedade".

A delimitação de parâmetros que determinem quais situações colocam os indivíduos sob risco e privação das suas necessidades sociais - aquelas que ocorrem sobre o indivíduo, mas que têm repercussões sociais - é um intento difícil de se precisar, dada a complexidade e variedade de condições e possibilidades de definições do que venha a ser cada uma delas. De acordo com Castel (2003, p. 61, tradução nossa), “[...] Um risco no sentido próprio da palavra é um acontecimento previsível, cujas chances de que ele possa acontecer e o custo dos prejuízos que trará pode ser previamente avaliado". Nesse sentido, no âmbito da proteção social, se considera os riscos sociais passíveis de serem indenizados por poderem ser mutualizados, como por exemplo: uma aposentadoria na velhice, um salário em substituição a um período em que o indivíduo sofra privação da capacidade do trabalho (doença, acidente, gravidez, desemprego), que podem se estender a seus dependentes, como é o caso das pensões.

Já as necessidades sociais apontam para um terreno ainda mais fluido e difícil de delimitar. De maneira simples, as necessidades de caráter social seriam aquelas ligadas às condições de vida e aos recursos que cada pessoa precisaria para atingir um patamar de existência aceitável em uma determinada sociedade, o que poderia ser chamado de um padrão mínimo de vida. (LEITE, 1978). Podemos considerar que uma das principais carências humanas ou necessidades sociais se constrói por meio da privação material, que comumente é identificada como pobreza. De um ponto de vista estritamente econômico, a pobreza pode ser traduzida enquanto situação de renda insuficiente para o atendimento das necessidades básicas. 
Desse modo, pode ser mensurada em vários níveis socioeconômicos, incluindo o da indigência.

Contudo, dada a complexidade da vida humana, a pobreza não pode ser resumida unicamente ao aspecto estritamente econômico ou à questão de renda. Existe um vasto patrimônio humano historicamente construído, tanto simbólico quanto material, cuja falta de acesso democrático ao mesmo representa condições de pobreza. Aqui nos referimos à cultura, política, educação, recursos tecnológicos e à riqueza econômica no sentido estrito socialmente produzida, que quando não repartida, deixa verdadeiras massas sociais à sua margem numa condição de grande carecimento.

Mas a grande questão é definir o que seria um padrão mínimo de vida aceitável para uma sociedade, frente à diversidade de circunstâncias reais de privações e riscos às quais os indivíduos estão expostos. Certamente, as respostas variarão conforme o modelo societário que a humanidade tem vivenciado ou desejado.

Por exemplo, como estabelecer esse padrão em um mundo capitalista, cuja característica preponderante é a produção e a reprodução de uma desigualdade estrutural, que é substanciada na desigualdade quanto às posições de classe? Além disso, de acordo com Mészáros (2011, p. 606), há desde os primórdios do capitalismo "[...] uma completa subordinação das necessidades humanas à reprodução de valor de troca - no interesse da auto-realização ampliada do capital". Conforme o autor, "[...] o que agora conta como 'necessidade' não é a necessidade humana dos produtores, mas os imperativos estruturais da própria valorização e reprodução do capital." (MÉSZÁROS, 2011, p. 606).

Todas essas questões informam a relação intrínseca e dilemática que existe entre a proteção social e o trabalho, que é, "[...] inescapável em sociedades divididas em classes, mormente na capitalista em curso." (PEREIRA, 2013b, p. 639). O dilema reside em primeiro lugar no tipo de trabalho que predomina no sistema capitalista, o assalariado, que gera como consequência a necessidade de

[...] lidar com o exército de reserva criado pelo próprio sistema para se reproduzir; ou de como fazer para evitar que os pobres aptos para o trabalho, mas sem trabalho, ao serem protegidos como sujeitos de direitos, fiquem "mal acostumados" e deixem de se guiar pela ética capitalista, de acordo com a qual só o trabalho eno- 
brece o homem e o livra da miséria material e moral. (PEREIRA, 2013b, p. 643, grifo do autor).

Aqui inserimos a categoria que consideramos central para uma abordagem crítica sobre a origem da necessidade de proteção social, sob as condições particulares que se processam no âmbito da sociedade do capital: a questão social, a qual se estabelece como resultado da conflituosa, contraditória e dialética relação entre capital e trabalho. Pensada sob perspectiva socio-histórica, essa categoria sintetiza-se na luta social de classe para satisfação de necessidades humanas. Nesse sentido, está fortemente ligada à luta de classes, aquela entre possuidores e possuídos, que marca a "[...] história de toda a sociedade até hoje" (MARX; ENGELS, 1997, p. 45).

Contudo, a questão social se apresenta de maneira particular no modo de produção capitalista, uma vez que está intimamente ligada às "[...] desigualdades engendradas pela emergência do trabalho 'livre' e toda a sequência de lutas por melhores condições de vida e de trabalho." (TEIXEIRA, 2008, p. 50, grifo da autora). A título de demarcação histórica, podemos considerar, de acordo com Castel (1998), que o surgimento do termo se deu nos anos 1830, referindo-se ao processo de pauperização massiva da população trabalhadora na Europa, e em especial na Inglaterra, em decorrência do impacto da expansão da industrialização. Foi nesse contexto que a proteção social "[...] transformou-se num dos mecanismos de enfrentamento da questão social, que expressa o conflito das relações sociais na sociedade capitalista e as contradições entre produção coletiva e apropriação privada da riqueza social.” (MENDES; WÜNSCH, 2009, p. 242).

Ou seja, partiu-se de formas rudimentares e corporativas de proteção, associadas às antigas expressões de solidariedade construídas nas corporações na vida no campo, às garantias mínimas para que os trabalhadores se submetessem às precárias condições de trabalho e salário oferecidas pelos capitalistas, no rápido processo de crescimento da indústria e das cidades (RODRIGUES, 2010).

Ao longo do processo de estruturação da proteção social pública, o desenvolvimento de legislações sociais, a exemplo da Poor Law na Inglaterra no século XIX, evidenciou a necessidade de uma maior intervenção do poder estatal na esfera econômica e cultural e demarcaram o reconhecimento público dos riscos sociais do trabalho assalariado. Assim, "[...] a generalização da obrigação de assegurar 
(que implica a garantia do Estado) foi a via real de constituição da sociedade da seguridade.” (CASTEL, 2003, p. 59, tradução nossa).

Dessa maneira, a conflituosa e dilemática relação entre trabalho e proteção social acentuou-se com a complexificação da sociedade capitalista, mas suas origens remontam ao período de "[...] decadência da sociedade feudal e da soberania da lei divina, elementos que configuravam a constituição das hierarquias políticas até final dos séculos XVI e XVII, quando é desencadeado um profundo debate sobre o papel do Estado." (BERING, 2006, p. 3). Isso ocorre no contexto da formação do Estado moderno, que surge como "[...] um aparato necessário à reprodução capitalista, assegurando a troca das mercadorias e a própria exploração da força de trabalho sob a forma assalariada." (BERING, 2006, p.18).

Desde então, uma trajetória de afirmação e negação do papel do Estado vem se desenvolvendo na história das sociedades modernas, e entre diferentes matrizes possíveis foram estruturados também diversos sistemas de proteção social. Seguiremos demonstrando algumas das principais perspectivas que informam esses sistemas. Posteriormente, discutiremos como no contexto da acumulação flexível as medidas flexibilizatórias nas relações de trabalho têm tensionado no sentido de uma prevalência da perspectiva de gerenciamento dos riscos sociais de maneira individualizada por parte dos trabalhadores. Finalmente, procuraremos demonstrar que esse debate assume formas e consequências diversas, entre os países de capitalismo central, como os europeus, e os de capitalismo periférico, como os da América Latina, dentre os quais o Brasil.

\section{PRINCIPAIS PERSPECTIVAS QUE INFORMAM A CONSTITUIÇÃO DE SISTEMAS DE PROTEÇÃO SOCIAL}

No século $\mathrm{XX}$, a conjugação de vários fatores fundou uma modalidade de proteção social, particularmente desenvolvida desde a Segunda Guerra Mundial, a partir dos países de capitalismo central, que ficou conhecida como Estado de bem-estar social ou Welfare State, nos países aglófonos e Etat Providence e Sozialstaat, na França e na Alemanha, respectivamente.

O surgimento do Estado de bem-estar foi um evento econômico, político e socialmente datado, que representou uma forte inflexão sobre as políticas sociais, uma vez que ao articulá-las em um 
"[...] sistema integrado de regulação social e econômica, comumente designado de "sistema de proteção social" ${ }^{1}$, passou a ser um componente fundamental das medidas anticrise após a crise de 1929." (BOSCHETTI, 2007, p. 26, grifo da autora).

No período propício ao desenvolvimento desse Estado social, nos países de capitalismo central foram desenvolvidos sistemas de proteção aliados a crescimento econômico e pleno emprego, onde foi possível arregimentar um volume significativo de ações e benefícios sociais, operacionalizados por políticas abrangentes e universalizantes. (BEHRING; BOSCHETTI, 2006). O fortalecimento dos partidos social-democratas, a difusão do fordismo como modelo de organização industrial e a imensa aceitação das propostas keynesianas foram elementos essenciais para a construção do conceito de seguridade social. (VIANNA, 2000). A conjunção desses três fatores foi fundamental para a consolidação do Estado de bem-estar enquanto democracia social dominante nas economias capitalistas avançadas, com feições particulares nos países periféricos. (AURELIANO; DRAIBE, 1989).

Nesse aspecto, tem sido recorrente entre os especialistas a constatação de que o surgimento de sistemas públicos de proteção social propriamente ditos confunde-se com o desenvolvimento da sociedade salarial, que segundo Castel (2003, p. 31, tradução nossa), "[...] não é apenas uma sociedade em que a maioria da população ativa é assalariada. É sobretudo uma sociedade na qual a imensa maioria da população acede à cidadania social a partir, antes de mais nada, da consolidação do estatuto do trabalho". As características desse trabalho, considerado típico ou regular nos países centrais, preponderantemente entre o Pós-Segunda Guerra Mundial e fins dos anos 1970, é o emprego estável, de tempo integral e protegido, no sentido do amparo pelo Estado no que se refere a direitos sociais e trabalhistas.

Munro (2007) informa que três principais justificativas estiveram influenciando a construção na noção de bem-estar desde que o Estado social começou a entrar na pauta pública como um dos seus principais provedores: a doutrina dos riscos; a dos direitos e a das necessidades. Segundo análise do autor,

[...] a escola de risco enfatiza falhas em mercados de seguros, especificamente a incapacidade de mecanismos de seguros privados e comunitários para cobrir todas as formas de risco, muitas vezes 


\begin{abstract}
devido a informações assimétricas ou incompletas. Essas importantes falhas nos mercados de seguros são agravadas por outras falhas nos mercados de trabalho, crédito e capital humano. A escola de direitos sociais e econômicos se concentra nas obrigações do Estado derivadas da afirmação de que os cidadãos possuem direitos sociais e econômicos que legalmente são reivindicações exigíveis no estado. Esses direitos costumam ser definidos na Declaração Universal dos Direitos Humanos e no Pacto Internacional de Direitos Econômicos, Sociais e Culturais, entre outras fontes de direito internacional, e freqüentemente são afirmados como provenientes da Lei Natural. A doutrina baseada nas necessidades enfatiza a importância prática e moral para os pobres e os não pobres de eliminarem (ou pelo menos aliviar ou reduzir) a pobreza e afirmam reivindicações morais e econômicas a favor de medidas de proteção social. (MUNRO, 2007, p. 1, tradução nossa).
\end{abstract}

A tensão entre essas linguagens sempre foi uma realidade que influenciou a construção dos padrões de proteção social no mundo. Mas a perspectiva dos direitos esteve influenciando significativamente o ordenamento jurídico internacional do trabalho, por meio das cartas de direitos humanos, das intervenções, convenções e/ou recomendações da OIT, dentre outros, com repercussões nas regulamentações das legislações sociais do trabalho nos países, o que ocorreu de formas e intensidades diferenciadas, conforme a posição de cada um na dinâmica mais ampla da reprodução ampliada do capital.

Contudo, as turbulências e incerteza instaladas no mundo do trabalho a partir do final dos anos 1960, apesar de não implicarem o desaparecimento completo da noção de bem-estar promovido pelo Estado, tem feito com que os sistemas de proteção social, inaugurados no segundo pós-guerra, venham "[...] perdendo, para o mercado, o protagonismo da regulação social compatível com a linguagem dos direitos." (PEREIRA, 2013a, p. 67).

Essa nova realidade pode ser percebida nos documentos de organismos internacionais nos quais constam os seus entendimentos sobre qual deve ser o escopo da proteção social que os países devem operar. Devereux e Sabates-Wheeler (2004) sintetizam definições de algumas agências internacionais sobre proteção social (Quadro 1). 
TRABALHO E PROTEÇÃO SOCIAL NA ACUMULAÇÃO FLEXÍVEL: individualização e gerenciamento do risco social

Quadro 1 - Definições de proteção social de agências internacionais

"A proteção social refere-se às ações públicas tomadas em resposta aos níveis de vulnerabilidade, riscos e privações que são consideradas socialmente inaceitáveis em uma determinada política ou sociedade". Overseas Development Institute (ODI)

"A proteção social é um conjunto de medidas destinadas a melhorar ou proteger o capital humano, que vão desde as intervenções no mercado de trabalho, o desemprego público ou o seguro de velhice até o apoio específico ao rendimento. As intervenções de proteção social ajudam os indivíduos, as familias e as comunidades a gerenciar melhor os riscos de renda que deixam as pessoas vulneráveis". Banco Mundial

"A proteção social é a 'prestação de beneficios às famílias e aos indivíduos através de acordos públicos ou coletivos de proteção contra o baixo nível de vida' ou o seu declínio". Organização Internacional do Trabalho (OIT)

"A proteção social é definida como 'o conjunto de políticas e programas destinados a reduzir a pobreza e a vulnerabilidade, promovendo mercados de trabalho eficientes, diminuindo a exposição das pessoas aos riscos e reforçando a sua capacidade de se protegerem contra riscos e interrupções/perda da renda". Asian Development Bank $(A D B)$

Fonte: DEVEREUX, S. ; SABATES-WHEELER, R. Transformative social protection. Brighton: Institute of Developmente Studies, oct. 2004. (IDS Working Paper, 232). Tradução nossa.

As noções de proteção social listadas acima apontam para a existência de uma proteção cujo objetivo é lidar com um conjunto estreito de problemas econômicos ou choques de subsistência, ou seja, proteger os indivíduos dos riscos inerentes ao sustento. Isso guarda relação direta com uma maior prevalência da proteção social enquanto uma resposta estritamente vinculada às consequências de eventos de incertezas e infortúnios aos quais os indivíduos particularmente possam ser acometidos em suas trajetórias de vida e profissional, prescindindo da análise dos determinantes socioeconômicos estruturais que incidem sobre o surgimento da condição de risco e vulnerabilidade.

A prevalência do paradigma dos riscos, em detrimento da linguagem do direito, pode ser atribuída ao fato de que a segurança vinculada ao estatuto do emprego estável e regular, típico do período predominantemente fordista-keynesiano, nos países de capitalismo 
central, estaria dando lugar à insegurança dos contratos flexíveis, parciais e por tempo determinado, próprios da nova fase da acumulação mundializada do capital.

Hoje se vivencia na Europa, por exemplo, uma maior complexificação, tanto com a presença de novos riscos quanto com o aumento da sensibilidade aos mesmos, já que a insegurança hoje é uma realidade para uma grande parte dos europeus. Segundo análise de Castel (2003), a extraordinária explosão da noção de risco está relacionada à hiperindividualização das práticas de privatização das seguridades. Essas transformações estariam obedecendo a uma lógica mais ampla de um escopo de políticas que tendem à individualização das proteções face às grandes transformações societais. Além disso, se apresentam como "[...] uma resposta à crise do Estado social que com seu funcionamento centralizado, administrador de regras universais e anônimas, se mostraria inadaptado em um universo cada vez mais diversificado e móvel." (CASTEL, 2003, p. 71, tradução nossa).

Assim, se a remodelagem no padrão produtivo flexível tem refletido nas relações de trabalho, levando a novas estruturações e padrões de regulação do mercado de trabalho também flexíveis, com tendência geral à redução do emprego regular em favor do emprego parcial, temporário e subcontratado, tem refletido também nos padrões de proteção social, tendentes a maior individualização e flexibilidade nas prestações.

\section{MEDIDAS FLEXIBILIZATÓRIAS E (IN)SEGURANÇA SOCIAL NA EUROPA}

As teses sobre flexibilização tomaram força inicialmente na Europa a partir dos anos 1970. No mundo da indústria avançada da Europa Ocidental, as ameaças concretas contra o status de segurança alcançado por diversos setores da sociedade na era do emprego estável e protegido fizeram emergir vários movimentos de classe contra a insegurança promovida pelo mercado e a diminuição da regulamentação das relações de trabalho pelo Estado.

A alta mobilidade do trabalhador tem se mostrado uma estratégia sobremaneira eficiente de adequação das necessidades voláteis do empregador sem que esse precise se preocupar com as garantias do empregado. O principal motivo para a implementação dessas medidas, na ótica neoliberal, seria a preservação do emprego frente à 
severa diminuição dos postos de trabalho estáveis e regulares. As teses neoliberais argumentam no sentido de que a regulação das relações de trabalho é um obstáculo à competitividade e ao investimento, principalmente pelo falto de que as leis protetoras do trabalho custam muito caro. Dessa forma, em resposta à pressão por redução do custo do trabalho para a garantia de rentabilidade e competitividade, multiplicaram-se na Europa, a partir dos anos 1970, as experiências de flexibilização dos salários. Para isso foram desenvolvidas estratégias de

[...] eliminação ou enfraquecimento das normas nacionais que protegiam o poder de compra dos assalariados e constituíam parte das fontes de 'rigidez' [...]. Foram desenvolvidas diversas formas de remuneração sem o caráter jurídico de salário (tais como participação nos lucros, stock options, distribuição de ações, etc). (FREYSSINET, 2009, p, 34).

A pressão pela queda do custo salarial direto e unitário foi seguida de um conjunto de medidas para impedir que o custo tendencial da proteção social onerasse a massa salarial, apesar das tensões contraditórias de estabilização da mesma em longo prazo, buscada pelos empregadores, como forma de garantir a reprodução social dos trabalhadores. Os desdobramentos são impacto direto na redução dos salários e enfraquecimento da proteção social e resultam em aprofundamento da desigualdade salarial onde,

[...] por um lado, os benefícios básicos (as chamadas prestations de base) tendem a se reduzir ao mínimo, estando ainda submetidos à disponibilidade de recursos. E mais, a manutenção desses direitos é algumas vezes dependente das condições da atividade dos 'beneficiários' (workfare). Enfim, nos países de tradição 'bismarckiana', nos quais o financiamento provém da cotização sobre os salários, uma transferência operou-se progressivamente em direção ao financiamento fiscal. O objetivo geral é, portanto, não somente reduzir o custo do Welfare State, mas também desconectá-lo do custo salarial, que constitui um componente particularmente rígido. (FREYSSINET, 2009, p, 35, grifos do autor).

Contudo, sob os auspícios das medidas neoliberais mais radicais, o surgimento na Europa da categoria working poor tem sido uma realidade, e o aumento da desigualdade de renda se faz presente em todo o mundo desenvolvido, já que a incapacidade de criação e manutenção de novos postos de emprego está contida numa crise sistêmica. 
A flexibilidade pressupõe a capacidade de adaptação das normas trabalhistas às novas relações de trabalho, que, na verdade, tem vindo comumente acompanhada de um processo de invalidação total ou parcial das normas e leis do trabalho. De todo modo, a busca pela flexibilidade fez com que os sistemas normativos nacionais se tornassem menos coercitivos e mais diversificados, sob o domínio da soft law, em que

$$
\begin{aligned}
& \text { [...] a norma obrigatória é substituída por um conjunto de mecanis- } \\
& \text { mos de pressão que supostamente favorecem a convergência em } \\
& \text { torno dos objetivos comuns. [...] a intervenção do Estado faz-se } \\
& \text { mais modesta e perde seu caráter imperativo; a negociação coleti- } \\
& \text { va, ali onde ela subsiste, faz-se descentralizada em direção à em- } \\
& \text { presa ou à unidade de produção, contribuindo para a diversificação } \\
& \text { e para a variabilidade das normas. (FREYSSINET, 2009, p, 41). }
\end{aligned}
$$

$\mathrm{O}$ autor refere-se também às tendências de maior flexibilidade do tempo de trabalho, numa relação interdependente entre esta, os salários e o emprego, cujos principais exemplos são os bancos de hora, as reduções nas jornadas de trabalho, os contratos a tempo parcial, dentre outros.

Mas é preciso considerar que, nem mesmo nos países centrais, os discursos e as experiências adquirem um padrão único. Assim como houve uma diversidade nos sistemas de proteção social no contexto do Welfare State, permanece havendo nas estratégias de conformação aos mais recentes desafios postos ao mundo do trabalho e, consequentemente, à proteção social do trabalhador. Jacques Freyssinet (2009) argumenta que apesar de ser convergente a ideia de uma tendência de crescimento da flexibilidade, há que se considerar a diversidade em que ocorre entre países e regiões do planeta, principalmente pelas características das distintas categorias de mão de obra. Além disso, os compromissos entre essas exigências contraditórias são mutáveis e " [...] variam em função das características das distintas fases do processo de acumulação, das estratégias adotadas pelas diferentes forças sociais e das relações de força que se estabelecem entre elas." (FREYSSINET, 2009, p. 29).

Nesse sentido, tem entrado em cena um componente que tem dado um novo tom à discussão sobre proteção social nos países centrais, a flexicurity ou flexiseguridade, como ficou mais conhecida nos países lusófonos, a partir da tradução em Portugal. Trata-se de uma alternativa contra a tendência de flexibilização mais radical àquela que se via ser proposta nas últimas duas décadas do século 
XX, no contexto das medidas neoliberais mais ortodoxas nos países de capitalismo central.

A flexicurity tem se tornado um conceito acadêmico e político influente, em particular desde que a União Europeia a transformou no coração de sua política estratégica de emprego. Em 2006, lançou o Livro Verde sobre as Relações Laborais da União Européia. Com inspiração nas estratégias advindas de países do Norte europeu, como a Dinamarca, a sua principal diretriz é a garantia de minimização dos impactos decorrentes das dispensas involuntárias e, por consequência, do crescimento das taxas de desemprego no continente.

O principal objetivo dessa política é desenvolver mecanismos de conciliar a flexibilidade dos mercados de trabalho e a segurança dos trabalhadores contra o desemprego. Ou seja, duas necessidades bastante antagônicas. Essa perspectiva de associação entre a flexibilidade e a seguridade põe em relevo um dos projetos que está ganhando espaço em todo o mundo, que é chamado modernização do Direito do trabalho, cuja premissa principal é que os princípios tradicionais do Direito do trabalho - dos quais o maior é o da proteção social ao trabalhador - são fatores que não favorecem o combate ao desemprego e nem a ampla concorrência.

Em uma análise crítica sobre a matriz da flexicurity, Burroni e Keune (2011) apresentam quatro aspectos que podem ser considerados limitações dessa proposta. Em primeiro lugar, sua ambiguidade em função de sua carga política; suas falhas em problematizar a discussão quanto à necessidade de criação de complementaridades do ponto de vista institucional; as lacunas em contemplar os conflitos de interesse existentes no contexto de mercados de trabalho cada vez mais heterogêneos e, finalmente, a visão reducionista presente na tentativa de conciliar a flexibilidade e a seguridade, já que são fatores de origens tão distintas.

Pode-se destacar, ainda, que, alinhado com a linguagem dos riscos sociais, prevalentes hoje nos discursos gerais sobre a proteção social no mundo, conforme consideramos acima, a proposta da flexicurity tem uma abordagem da relação de trabalho baseada no direito individual, em oposição às negociações coletivas, baseadas nas representações sindicais e de classe. A prevalência é pela individualização das negociações e dos acordos trabalhistas, o que contra- 
ria o princípio da não isonomia presente na relação de trabalho, que informa o Direito do Trabalho clássico.

\title{
4 ALGUMAS DAS PARTICULARIDADES DAS MEDIDAS FLEXIBILIZATÓRIAS NA AMÉRICA LATINA E BRASIL
}

Apesar de o momento ser sobremodo desfavorável para a classe trabalhadora e para a proteção social pública, universalista e na perspectiva do direito, diante do desenvolvimento das medidas de flexibilização, nos países do capitalismo central tem-se buscado manter, no geral, o controle no que se refere às despedidas e a um padrão mínimo de proteção ao trabalho. Na América Latina, por sua vez, o movimento tem sido bem mais agressivo, onde se adota o que tem sido chamado de

\begin{abstract}
[...] 'flexibilização selvagem', que é a revogação ou modificações de algumas normas legais de proteção ao trabalhador e ampliação da franquia para reduzir direitos e condições de trabalho, seja por meio de contratos coletivos, seja por meio de atos unilaterais do empregador. (CAVALCANTI, 2008, p. 162, grifos da autora).
\end{abstract}

A apreensão das determinações desse fenômeno no contexto dos países do capitalismo periférico requer matizar a análise frente à condição de superexploração da força de trabalho, que amplia a degradação e a precariedade do trabalho a níveis muito elevados, já que ocorrem em um contexto onde a questão social é aguda e envolve grandes contingentes populacionais em cada país. No contexto da América Latina e Brasil, essa realidade representa um agravante ao avanço da perspectiva de risco sobre a constituição dos sistemas de proteção social, que visa à substituição da perspectiva de seguridade social, mais abrangente e universalista, propondo em seu lugar ações de caráter individualizado e privatizado.

Para Asa Cristina Laurell (1998, pp. 187, 188), “[...] a questão dos Estados de bem-estar na América Latina é bastante polêmica, pois é verdade que a proteção social, os serviços e os benefícios carecem de universalidade e equidade". A autora faz essa afirmação tendo em vista o elevado grau de pobreza da maioria da população dos países da região, que, na sua interpretação, é resultante de uma distribuição extremamente desigual de riqueza e renda, e não da falta de capacidade desses países em satisfazer as necessidades básicas dos seus povos. (LAURELL, 1998). 
É fato o caráter residual e regressista que assume a proteção social e as medidas de bem-estar na maioria dos países latino-americanos. Não é facilmente identificável nesses países a estruturação típica de um Estado social e de uma economia caracterizados pelas situações de "[...] pleno-emprego, acompanhada de uma subida persistente do salário real, [que] eleva os níveis de vida da esmagadora maioria da população, como ocorreu no [...] quadro histórico do Welfare State dos países desenvolvidos." (AURELIANO; DRAIBE, 1989, p. 150). Pelo contrário, nessa região, para a grande maioria da população prevaleceram os baixos salários e para uma parte expressiva não houve e ainda não há o chamado emprego regular ou típico.

No Brasil, a despeito da Constituição Federal (CF) de 1988 conter princípios que apontam para uma maior cobertura em termos de proteção social, balizada na perspectiva do direito e estruturada na forma de Seguridade Social, um movimento por parte do grande capital e da burocracia estatal tem procurado sublimar as conquistas obtidas pela classe trabalhadora, sob alegação da inadequação do modelo de Seguridade Social à necessária modernização das relações de trabalho que tem sido o mote das sucessivas ondas de reformas neoliberais.

Desde os anos 1990 o avanço do neoliberalismo e das medidas flexibilizatórias no Brasil e, consequentemente, a redução do Estado no campo social apresenta um novo paradoxo para a proteção social no país. Uma vez que se alcançou tardiamente em algum nível a estruturação de um sistema na perspectiva do direito, não houve espaço para o seu amadurecimento democrático, convivendo com uma dinâmica econômica desfavorável em nível global e internamente com um fraco apoio político para sua sustentação. E na conjuntura política e econômica conturbada que vivencia o Brasil atual, o governo de Michel Temer, Partido do Movimento Democrático Brasileiro (PMDB), desde que assumiu a Presidência da República, em 2016, até o momento em que estamos redigindo essas linhas, tem posto em curso uma grave ofensiva contra os direitos dos trabalhadores por meio da reforma trabalhista, da regulamentação do trabalho intermitente, da liberação da terceirização das atividades-fim, da reforma da Previdência, assim como por meio de medidas de corte de gastos públicos, em especial na área social. É flagrante o alinhamento dessas reformas com a perspectiva da individualização e privatização do gerenciamento do risco social e do trabalho, conforme analisado anteriormente. 


\section{CONCLUSÃO}

Apesar do seu caráter contraditório enquanto mediadora da dilemática relação entre capital e trabalho, em especial no contexto periférico e dependente, a proteção social pode ser considerada um instrumento de justiça social, enquanto um mecanismo de redistribuição da riqueza socialmente produzida e profundamente concentrada. Pode, inclusive, estar a serviço do aprofundamento da democracia popular nesses países, onde se inclui o Brasil.

O contexto atual, tanto no Brasil quanto no mundo, é de grandes incertezas, embora em meios às incertezas exista algo que parece inequivocamente certo: que em todas essas medidas o que prevalece é a busca por alternativas que garantam a reprodução ampliada do capital, que agora assume uma significativa fluidez no contexto flexível.

As ambiguidades e tensões que subjazem as medidas flexibilizatórias tornam evidente que não é ponto pacífico, nem no capitalismo central, que tais medidas resolvam os impasses gerados no mundo do trabalho nessa nova fase de acumulação. Por meio das medidas mais ortodoxas não se alcançou o aumento do emprego e a diminuição da pobreza. Também não é certo que essas metas sejam alcançadas com outras estratégias ou alternativas, no estilo flexisegurança, tal como se propala, menos ainda no estilo flexibilização selvagem, no contexto periférico e dependente.

No Brasil, e demais países latino-americanos, o contexto de insegurança social e privação das necessidades básicas, vivenciado pela grande maioria da classe trabalhadora, evidencia a importância da proteção social pública, universalista e na perspectiva do direito, que abarque toda a complexidade e necessidade social dos trabalhadores e cidadãos, não obstante os modelos existentes ainda serem restritivos e seletivos. Isso indica que as condições de vida da população não são compatíveis com o fim da proteção social e trabalhista, mas sim, com a sua ampliação e com seu aperfeiçoamento, enquanto medida de fortalecimento da democracia, uma vez que se estará atendendo às demandas efetivamente populares e não apenas de pequenos grupos hegemônicos. 
TRABALHO E PROTEÇÃO SOCIAL NA ACUMULAÇÃO FLEXÍVEL: individualização e gerenciamento do risco social

\section{REFERENCIAS}

AURELIANO, L.; DRAIBE, S. M Teorias e Tipologias sobre a Emergência e Desenvolvimento do Welfare Stare. In: BRASIL. Ministério da Previdência e Assistência Social; COMISSÃO ECONÔMICA PARA AMÉRICA LATINA E CARIBE. Projeto: A política social em tempo de crise: articulação institucional e descentralização - reflexões sobre a natureza do bem estar. Brasília, DF, 1989. p. 86-179. (Economia e Desenvolvimento, n. 3).

BEHRING, E. R. Fundamentos de política social. In: MOTA, A. E. et al. Serviço social e saúde: formação e trabalho profissional. São Paulo: OPAS, OMS, Ministério da Saúde, 2006. p. 13-39.

; BOSCHETTI, I. Política social: fundamentos e história. São Paulo: Cortez, 2006. (Biblioteca básica de serviço social, v. 2).

BOSCHETTI, I. Seguridade social na América Latina após o dilúvio neoliberal. Observatório da Cidadania, Rio de Janeiro, v. 11, p. 91-98, 2007.

BURRONI, L; KEUNE, M. Flexicurity: a conceptual critique. European Journal of Industrial Relations, [S. 1.], v. 17, n. 1, p. 75-91, 2011.

CASTEL, R. As metamorfoses da questão social: uma crônica do salário. Tradução de Iraci D. Poleti. Petrópolis, RJ: Vozes, 1998.

L'insecurité sociale: qu'est-ce que'être protégé? Paris: Éditions du Seuil et La Réplublique des Idées, 2003.

CAVALCANTI, L. M. de G. B. A flexibilização do direito do trabalho no Brasil: desregulação ou regulação anética do mercado? São Paulo: LTr, 2008.

DEVEREUX, S. ; SABATES-WHEELER, R. Transformative social protection. Brighton: Institute of Developmente Studies, oct. 2004. (IDS Working Paper, 232).

FREYSSINET, J. As trajetórias nacionais rumo à flexibilidade da relação salarial: a experiência europeia. In: GUIMARÃES, N. A.; HIRATA, H.; SUGITA, K. (Orgs.). Trabalho flexível, empregos precários?: uma comparação Brasil, França, Japão. São Paulo: EDUSP, 2009. p. 16-48.

JACCOUD, L. Proteção social no Brasil: debates e desafios. In: BRASIL. Ministério do Desenvolvimento Social e Combate à Fome; ORGANIZAÇÃO DAS NAÇÕES UNIDAS PARA A EDUCAÇÃO, 
A CIÊNCIA E A CULTURA. Concepção e gestão da proteção social não contributiva no Brasil. Brasília, DF, 2009. p. 57-86.

LAURELL, A. C. Para um novo Estado de bem estar na América Latina. Lua Nova: Revista de Cultura e Política, São Paulo, n. 45, p. 187-204, 1998.

LEITE, C. B. A proteção social no Brasil. 2. ed. São Paulo: LTr, 1978.

MARX, K.; ENGELS, F. Manifesto do Partido Comunista. Lisboa: Avante, 1997. Disponível em: <www.pcp.pt/manifesto-do-partidocomunista-edições-avante-1997>. Acessado em: 29 jun. 2016.

MENDES, J. M. R.; WÜNSCH, D. S. Trabalho, classe operária e proteção social: reflexões e inquietações. Revista Katálysis, Florianópolis, v. 12, n. 2, p. 241-248, jul./dez. 2009.

MÉSZÁROS, I. Para além do capital: rumo a uma teoria da transição. Tradução: Paulo Cezar Castanheira, Sérgio Lessa. 1. ed. rev. São Paulo: Boitempo, 2011.

MUNRO, L. T. Risks, rights, and needs: compatible or contradictory bases for social protection? Manchester: Brooks World Poverty Institute, oct. 2007. (BWPI Working Paper, 7).

PEREIRA, C. P. Proteção Social no Capitalismo: contribuições à crítica de matrizes teóricas e ideológicas conflitantes. 2013. $307 \mathrm{f}$. Tese (Doutorado em Serviço Social) - Programa de Pós-Graduação em Política Social, Universidade de Brasília, Brasília, DF, 2013a.

, P. A. P. Proteção social contemporânea: cui prodest? Serviço Social e Sociedade, São Paulo, n. 116, p. 636-651, out./dez. 2013 b.

RODRIGUES, P. F. V. Proteção social e as transformações do trabalho. Serviço Social e Saúde, São Paulo, v. 9, n. 2, p. 103-122, dez. 2010.

TEIXEIRA, S. M. Envelhecimento e trabalho no tempo do capital: implicações para a proteção social no Brasil. São Paulo: Cortez, 2008.

VIANNA, M. L. T. W. A americanização (perversa) da seguridade social no Brasil: estratégias de bem-estar e políticas públicas. 2. ed. Rio de janeiro: Revan: UCAM, IUPERJ, 2000.

\section{Nota}

1 Para Boschetti (2007, p. 26), o que configura a existência de um sistema de proteção social é, "'[...] o conjunto organizado, coerente, sistemático, planejado de diversas políticas sociais, financiado pelo fundo público e que garante proteção social por meio de amplos direitos, bens e serviços sociais, nas áreas de emprego, saúde, previdência, habitação, assistência 
TRABALHO E PROTEÇÃO SOCIAL NA ACUMULAÇÃO FLEXÍVEL: individualização e gerenciamento do risco social

social, educação, transporte, entre outros bens e serviços públicos. Tem como premissa o reconhecimento legal de direitos e a garantia de condições necessárias ao exercício do dever estatal para garanti-los". 
